\title{
Assessing dynamics of palm oil import demand: the case of six Asian countries
}

\begin{abstract}
This article uses annual data to investigate the palm oil import demand in selected Asian countries (India, China, Japan, Bangladesh, Korea, and Pakistan) through using the autoregressive distributed lag (ARDL) technique. The findings of the study show that the palm oil and substitute oils prices and the national income of the importing countries are significant determinants of palm oil demand across the six models. Other factors such as biofuel mandate, trade policies, and exchange rate also proved to be important factors affecting import demand for palm oil in some of these countries.
\end{abstract}

Keyword: ARDL; Bounds test; Import demand; Palm oil 